\title{
Interpersonal Community Psychiatric Treatment for non-psychotic chronic patients and nurses in outpatient mental health care: A controlled pilot study on feasibility and effects
}

\author{
B. Koekkoek ${ }^{\text {a,b,* }}$, B. van Meijel $^{\text {c }}$, A. Schene ${ }^{\text {d }}$, A. Smit ${ }^{a}$, A. Kaasenbrood ${ }^{\text {a }}$, G. Hutschemaekers ${ }^{\text {a,e }}$ \\ a ProPersona Mental Health Care, Wolfheze, The Netherlands \\ ${ }^{\mathrm{b}}$ Arnhem and Nijmegen University of Applied Sciences, Research Group Social Psychiatry \& Mental Health Nursing, Nijmegen, The Netherlands \\ ${ }^{\mathrm{c}}$ Inholland University of Applied Sciences, Research Group Mental Health Nursing, Amsterdam, The Netherlands \\ ${ }^{\mathrm{d}}$ Department of Psychiatry, Academic Medical Centre, University of Amsterdam, Amsterdam, The Netherlands \\ ${ }^{\mathrm{e}}$ Academic Centre of Social Sciences, Radboud University, Nijmegen, The Netherlands
}

\section{A R T I C L E I N F O}

\section{Article history:}

Received 7 April 2011

Received in revised form 8 October 2011

Accepted 4 November 2011

\section{Keywords:}

Mental health care

Long-term care

Illness behaviour

Nurse-patient relations

Mixed-methods research

'Difficult' patients

Community mental health nursing

\begin{abstract}
A B S T R A C T
Background: In psychiatric care professionals perceive some patients as 'difficult', especially patients with long-term non-psychotic disorders. For these patients few evidence-based treatments exist. An intervention program, Interpersonal Community Psychiatric Treatment (ICPT), was developed by the authors. It was evaluated with the aim to increase effective behaviours by both patients and community psychiatric nurses (CPNs).

Objective: To assess the feasibility and effectiveness of an intervention program for use by CPNs in the care of 'difficult' patients with non-psychotic chronic disorders, in a controlled pilot study.

Design: A mixed-methods quasi-experimental study using process and outcome measures across several dimensions. Measurements took place at 0,3 , and 6 months.

Settings: Three community mental health centres in the centre of The Netherlands.

Participants: 14 CPNs and 36 long-term non-psychotic patients who were perceived as 'difficult' were selected. Patients were offered either ICPT (20) or care as usual (16). All patients and CPNs could be followed up at all measurements.

Methods: Quantitative data included type and severity of psychiatric disorder, psychosocial functioning, needs for care, quality of life and social participation. Also, service use, satisfaction with care, and quality of the therapeutic alliance were measured. Qualitative interviews were conducted with all CPNs and patients in the experimental group.

Results: ICPT was found feasible by both CPNs and patients. Both the experimental and control condition showed improvement on a number of outcomes. ICPT, however, resulted in significantly better results in some areas. Patients' social network size increased and their care utilization decreased. Also, the quality of the working alliance increased and perceived patient difficulty decreased, both as scored by professionals.

Conclusions: ICPT is one of very few intervention programs aimed at 'difficult' nonpsychotic chronic patients. In this pilot study was found that it can be successfully carried out by CPNs, is generally experienced as acceptable and useful by patients and CPNs alike, and results in some significantly better effects on both process and outcome measures. In
\end{abstract}

\footnotetext{
* Corresponding author at: ProPersona Mental Health Care, 6874 BE Wolfheze, The Netherlands.

E-mail addresses: b.koekkoek@propersona.nl (B. Koekkoek), berno.vanmeijel@inholland.nl (B. van Meijel), a.h.schene@amc.uva.nl (A. Schene), a.smit@propersona.nl (A. Smit), a.kaasenbrood@propersona.nl (A. Kaasenbrood), g.hutschemaekers@acsw.ru.nl (G. Hutschemaekers).
} 
the main study, some alterations will be made to the instruction manual and training program. Also, the diagnostic interview may be briefer, and the characteristics and treatment integrity of CPNs will be included in measurements. Further controlled and randomized research is needed to test the effectiveness of the program in a larger group of patients.

(c) 2011 Elsevier Ltd. All rights reserved.

\section{What is already known about the topic?}

- In mental health care certain non-psychotic patients are perceived as 'difficult'.

- Patients perceived as 'difficult' patients run the risk to receive lower quality of care.

- Community psychiatric nurses have few evidence-based interventions to work effectively with non-psychotic patients in long-term care, in particular with those that they perceive as 'difficult'.

\section{What this paper adds}

- A structured outpatient nursing program that is based on empirical and theoretical knowledge is feasible for both patients and professionals.

- The program results in positive outcomes for both patients and professionals.

- Even with a challenging population such as 'difficult' long-term non-psychotic patients positive outcomes may be achieved.

\section{Introduction}

Over the last few decades, community mental health care for patients with severe mental illness (SMI) has developed into a practice with an increasingly solid base of evidence (e.g. Torrey et al., 2001). In quite some countries across the globe, nurses are the primary professional caregivers of these patients in outpatient psychiatric care (WHO, 2007). There still is some debate among researchers and clinicians about which mental disorders meet the SMIqualification according to DSM-IV criteria. Consequently, views on the allocation of resources also vary. Some argue that only people with psychotic disorders qualify, others argue that all disorders do as long as the patient receives long-term care and is disabled in social functioning (Ruggeri et al., 2000). The latter definition also includes non-organic non-psychotic disorders such as long-term depressive disorders, anxiety disorders, substance use disorders and personality disorders. The proportion of patients with non-psychotic disorders among those with severe mental illness is estimated at $40 \%$ (Ruggeri et al., 2000). Despite the fact that such non-psychotic disorders are highly frequent, serious, enduring, and highly disabling (Barr, 2000; Bowers, 1997), their severity has been questioned. Some nursing leaders have, for instance, claimed that scarce resources should be spent solely on patients with schizophrenia and other psychotic disorders (Gournay and Brooking, 1994; Gournay, 1995).

Interventions for patients with non-psychotic disorders have been less developed (Curran and Brooker, 2007), possibly since professionals may consider these patients as less deserving of psychiatric (nursing) care (Koekkoek et al., 2006). They are seen as more able to control their behaviours, both outside and within psychiatric services, than are patients with psychotic disorders (e.g. Hinshelwood, 1999). This becomes especially problematic when non-psychotic patients display challenging behaviours, such as not showing upon appointments, being demanding, and performing self-harming or suicidal actions. In the absence of evidence-based interventions, care giving may be highly challenging and patients may be perceived as 'difficult' (Breeze and Repper, 1998). Since these patients, regardless of the nature of diagnosis, have long-term problems, several disabilities and high needs for care (e.g. Hayward et al., 2006; Koekkoek et al., 2010a), we have focussed on intervention development for this group of non-psychotic chronic patients-i.e. patients with a non-psychotic diagnosis that have received psychiatric care for longer than two years. Typically, non-psychotic chronic patients are diagnosed with a multitude of disorders, such as depressive and anxiety disorders, personality disorders, and often also substance use disorders-resulting in a mix of partly overlapping classifications. Within this group we specifically targeted patients who have repeated disagreements with their treating professionals over form and content of treatment, and who often are considered 'difficult'.

In our previous work, we investigated the problems that community psychiatric nurses (CPNs), other professionals, and patients experience in current psychiatric care for these patients (Koekkoek et al., 2009). We found that care often lacks a focus, a theoretical view, and a methodological structure. Although pertinent to this patient group, these issues extend to (community) psychiatric nursing in general (e.g. MacNeela et al., 2010; Goossens et al., 2008). Therefore, intervention development and evaluation is highly necessary. In this paper we report on a controlled pilot study of the feasibility and effectiveness of a program of community psychiatric nursing care for 'difficult' patients with nonpsychotic chronic disorders, called Interpersonal Community Psychiatric Treatment (ICPT).

\section{Background}

The development of ICPT took place over a period of four years and was guided by the principles of Intervention Mapping (Bartholomew et al., 1998). After conducting two literature reviews (Koekkoek et al., 2006, 2010b) and empirically investigating the problems in current care from different viewpoints (i.e. experts, professionals and patients), we integrated the findings from these studies into a theoretical model. This model, presented elsewhere in more detail (Koekkoek et al., 2011), explains the 
Table 1

Socio-demographic and clinical characteristics of experimental group $(n=20)$ and control group $(n=16)$.

\begin{tabular}{|c|c|c|c|}
\hline Characteristics & $\begin{array}{l}\text { Experimental group } \\
n(\%)\end{array}$ & $\begin{array}{l}\text { Control group } \\
n(\%)\end{array}$ & $p$ \\
\hline Women & $15(75.0)$ & $10(62.5)$ & .418 \\
\hline Marital status & & & .728 \\
\hline Married/living together with partner & $5(25.0)$ & $3(18.8)$ & \\
\hline Unmarried & $12(60.0)$ & $9(56.3)$ & \\
\hline Divorced & $3(15.0)$ & $4(25.0)$ & \\
\hline Ethnicity & & & .813 \\
\hline Dutch & $18(90.0)$ & $14(87.5)$ & \\
\hline Other & $2(10.0)$ & $2(12.5)$ & \\
\hline Education & & & .279 \\
\hline Elementary school & $4(20.0)$ & $1(6.3)$ & \\
\hline High school & $8(40.0)$ & $10(62.5)$ & \\
\hline College/Graduate/Professional & $6(30.0)$ & $5(31.3)$ & \\
\hline Not given & $2(10.0)$ & 0 & \\
\hline Employment & & & .036 \\
\hline Volunteer, protected or paid work & $1(5.0)$ & $5(31.3)$ & \\
\hline No work (including disability) & $19(95.0)$ & $11(68.8)$ & \\
\hline Source of income & & & .133 \\
\hline Disability & $15(75.0)$ & $7(43.8)$ & \\
\hline Welfare & $5(25.0)$ & $7(43.8)$ & \\
\hline Height of monthly income & & & .012 \\
\hline$<1000$ euro & $14(70.0)$ & $5(31.3)$ & \\
\hline \multirow[t]{2}{*}{$>1000$ euro } & $5(25.0)$ & $11(68.8)$ & \\
\hline & Mean [range] (SD) & Mean [range] (SD) & $p$ \\
\hline Axis I disorders (lifetime) & $3.9[0-6](1.6)$ & $3.4[1-7](1.7)$ & .407 \\
\hline Axis II disorders & $2.4[0-6](1.8)$ & $2.8[0-6](1.8)$ & .511 \\
\hline Age in years & $41.1[22-59](10.1)$ & $43.2[31-57](8.1)$ & .523 \\
\hline Number of years in treatment in CMHC & $10.1[2-17](6.0)$ & $4.3[1-9](2.8)$ & .001 \\
\hline Global Assessment of Functioning score & $46.2(7.7)$ & $47.4(6.0)$ & .621 \\
\hline
\end{tabular}

problems between patients and professionals from the perspective of learned ineffective behaviour by both parties. Chronic ineffective illness behaviour refers to patient behaviours such as being clinging, disqualifying of the professional's competence, and demanding in relation to the professional, often accompanied by high service use. Chronic ineffective professional behaviour refers to professional behaviours such as ignoring patient needs, failing to set limits and maintain treatment structure, and doing not much more than managing the situation without letting it run out of hand too much.

\section{Purpose statements}

The aims of this paper are (1) to describe the content of ICPT, (2) to assess the feasibility of ICPT through interviews, both in patients and professionals, and (3) to assess the preliminary effects of ICPT on outcome and process measures.

\section{Methods}

\subsection{Design}

A mixed-methods quasi-experimental design was used, combining pre-post and longitudinal assessments of outcome in both patients and professionals to establish the effects of the program, compared to the outcome in a control group. Longitudinal process measures and qualitative interviews with patients and professionals were used to establish the program's feasibility.

\subsection{Sample/participants}

The study setting consisted of three case management teams in the centre of the Netherlands. Inclusion criteria for patients were a main non-psychotic diagnosis, two years or longer in psychiatric care, poor psychosocial functioning (GAF-score $\leq 50$ ), age $18-60$ years, and Dutch literacy. Exclusion criteria were current psychotic disorders (except short, reactive psychotic episodes), bipolar disorders, and organic disorders. Comorbid disorders, including substance use disorders, were allowed. Further selection took place through the addition of the criterion of professional-perceived difficulty, operationalized as the presence of disagreement over content and/or form of treatment with at least two professionals over the last two years. Patients' eligibility was assessed by the team leader (a CPN) and the consulting psychiatrist, and was checked with the authors.

Eligible patients underwent a structural diagnostic interview for Axis I-disorders (SCID-I; Williams et al., 1992) and Axis II-disorders (SCID-II; First et al., 1995), based on DSM-criteria for assessment of psychiatric disorders. These interviews were conducted by four Master-level trained psychiatric nurses, two Master-level trained social scientists, and a psychiatrist. All were trained by an experienced interviewer according to the SCIDs' instruction manuals. 


\subsection{Interventions}

\subsubsection{Experimental condition}

Interpersonal Community Psychiatric Treatment (ICPT) was specifically designed for community mental health professionals to use with 'difficult' non-psychotic chronic patients. The method of Intervention Mapping was applied to systematically develop the program (see Koekkoek et al., 2010c for a detailed description of its development and content). Theoretically, ICPT is based on an interpersonal explanation for the problems between patients and professionals, using the perspective of learned ineffective behaviour by both parties (see Koekkoek et al., 2011 for details of this concept). A model of treatment stages, based on prior research, was expanded with interventions extracted from evidencebased treatments and current best practices. The program was repeatedly discussed in a working group of community mental health experts (consisting of nurses, psychiatrists, and psychologists).

The goal of ICPT is to decrease ineffective behaviours by patients and professionals. It aims to reach this goal through involving patients more actively into their treatment process, and through supporting professionals to structure the treatment process more clearly. Hereto, generic interventions (e.g. treatment structure) and specific interventions (e.g. needs assessments and therapeutic techniques) are used. ICPT consists of three elements: (1) a general structure of treatment stages, (2) specific therapeutic methods per stage, and (3) general methodical elements per session (i.e. setting an agenda, discussing goals, looking back on the session).

The treatment process starts with stage 1 ('alliance'), in which optimization of the therapeutic alliance is the focus and relationship management (Dawson and MacMillan, 1993; Hoch et al., 2006) is the specific therapeutic method. The 2nd stage ('refinement') focuses on the development of, negotiation about, and agreement over treatment goals in which motivational interviewing (Miller and Rollnick, 2002; Burke et al., 2003) is the specific method. The 3rd stage ('working') focuses on improvement of the level of activities and participation, in line with earlier agreed on treatment goals. Two specific methods are used here: clinical case management (Suber, 1994; Ziguras and Stuart, 2000) and structured analysis of interpersonal behaviour (Linehan, 1993; McCullough, 2000; Keller et al., 2000). The general methodical elements are used in each session (see 2 nd column of Table 3 for a detailed description).

The frequency of sessions and the length of the program are dependent on mutually agreed needs and goals. Generally an ICPT-session takes place every two weeks and has a duration between 20 and $45 \mathrm{~min}$. The case management team consisted of six CPNs, who offered ICPT in cooperation with the team's two consulting psychiatrists. All had received three days of ICPT-training in the month previous to the start of the study, offered by the developer of the program and supported by subject-specific sessions by specialized scientists-professionals.

\subsubsection{Control condition}

The control group received community psychiatric nursing care as usual, which is widespread in Dutch mental health care, and generally functions according to case management principles (e.g. Suber, 1994). These care as usual sessions take place on average every two weeks with a duration of $20-45 \mathrm{~min}$. Care is not formalised or manualised but consists of an eclectic mix of different modalities, of which psychosocial support is the most important. In the existing literature there is no mention of formal goals of this care as usual, yet it seems centred on maintaining the patient's present health status and offering interventions on a predominantly ad hoc basis (see also Koekkoek et al., 2010b). The case management team consisted of $10 \mathrm{CPNs}$ and 2 consulting psychiatrists. None of them was trained in, or familiar with the ICPT program.

\subsection{Measures}

Since establishing meaningful health outcomes in SMIpatients is complicated due to often limited progress (Montgomery et al., 2009), we used the WHO International Classification of Functioning, Disability and Health (ICFDH; Ustun et al., 2003) to distinguish between disease (body structures and functions), disability (activity limitations) and functioning (participation limitations). In psychiatry, these three concepts usually are interpreted as the type and severity of psychiatric disorder (functions), psychosocial functioning (activity limitations), and quality of life and social participation (participation limitations). In addition, important process measures in mental health care are service use, satisfaction with care, and quality of the therapeutic alliance.

\subsubsection{Quantitative measures}

According to the ICFDH-model we measured outcomes across three levels.

- Severity of psychiatric disorder.

o OQ-45 (Outcome Questionnaire; Lambert et al., 1996): a 45-item patient-rated instrument which assesses treatment outcome, mostly in terms of symptom reduction.

- HoNOS (Health of the Nation Outcome Scale; Bebbington et al., 1999): a 12-item clinician-rated instrument to assess general mental health in predominantly SMIpatients.

- Disability and psychosocial functioning.

- GAF-score (Global Assessment of Functioning; Goldman et al., 1992): a single-item clinician-rated composite score between 10 and 100 of psychiatric and social functioning.

- CANSAS (Camberwell Assessment of Need Short Appraisal Schedule; Phelan et al., 1995): a 22-item instrument that measures met, unmet, and total needs for care as viewed by both the patient and the caregiver.

- Participation and quality of life.

- MANSA (Manchester Short Assessment of Quality of Life; Priebe et al., 1999): a 16-item patient-rated 
instrument that assesses quality of life in SMIpatients.

- Extent of social network: a single patient-informed question on the extent of the individual's social network, measured as ordinal categories.

We assessed process with the following measures:

- Service use.

- CSSRI-EU (Client Socio-Demographic and Service Receipt Inventory; Chisholm et al., 2000): a patientinformed instrument that captures all health care and social services use, as well as any justice department contacts.

- CMHC's administrative records (ARs): the organisation's administrative records that register all care contacts by patients in the CMHC.

- Satisfaction.

- CSQ-8 (Client Satisfaction Questionnaire; Attkisson and Zwick, 1982): an 8-item patient-administered instrument that assesses satisfaction with care.

- WSQ (Work Satisfaction Questionnaire): a professionaladministered composite instrument, consisting of a 21item scale measuring satisfaction (Landeweerd et al., 1996), an 8-item scale measuring autonomy, and a 10item scale measuring social support (de Jonge, 1995).

- Therapeutic alliance.

- STAR (Scale To Assess the Therapeutic Relationship; McGuire-Snieckus et al., 2007): a 12-item instrument that measures the quality of the therapeutic alliance in community mental health care, administered by patients (STAR-P) and clinicians (STAR-C). We used a Dutch version of which the back-translation was approved of by the original developer.

- Professional-perceived patient difficulty.

- Difficult patient score (Koekkoek et al., 2010a): a professional-rated 7-point score of the patient's perceived 'difficulty'.

- Relation of ICPT-fidelity (offered by professional) and session rating score (by both patient and professional) (each session).

- ICPT-form: a professional-administered checklist of the number of ICPT-elements used in each face-toface contact. The order of the checklist followed the chronological order of the treatment stages in ICPT. The scoring schedule rated the different elements in such a way that, regardless of the treatment stage, scores may vary between 4 and 10 (see 3rd column of Table 3 for scoring schedule).

- SRS (Session Rating Scale; Duncan et al., 2003): a brief instrument using four visual analogue scales to rate (1) the alliance with the other, (2) the fit of the goals and topics worked on, (3) the fit with the other's approach or method, and (4) the session in general. At the end of each face-to-face contact, the SRS was filled out by both the patient and the professional. One item in the professionals' version was modified to tailor it to the professional's perspective ('the therapist's approach is a good fit for me' was changed into 'the client's approach is a good fit for me').

\subsubsection{Semi-structured interviews}

Qualitative data was collected from three different data sources:

- individual patient interviews at 6-month follow up;

- individual professional interviews at 6-month follow up;

- minutes and recordings of biweekly team supervision meetings during 6 months.

Patients' and professionals' experiences with the intervention program were collected through a semistructured interview that was digitally recorded. The patient interview consisted of a number of closed (yes/no) and open questions. This interview covered the following items: changes in the treatment received, the feasibility and usefulness of these treatment elements, and the overall impression of the treatment. The professional interview consisted of a number of scaling (1-10) and open questions. This interview covered the following items: personal competence in administering ICPT, the quality of the instruction manual and training program, the feasibility of ICPT in general and with certain patients, and the added value of team supervision. Team supervision sessions were also digitally recorded and minutes were collected from each meeting.

\subsection{Procedures and data analysis}

All measures were obtained at baseline and 6-month follow-up. Therapeutic alliance and service use were also measured at 3-month follow up. All statistical procedures were performed with SPSS version 15. After controlling for normal distributions, Poisson-distributions were found necessary for skewed service use data. Paired $t$-tests were used to assess within-group differences between baseline and 6-month follow-up scores. Since there were some differences between groups at baseline, of which the number of years in psychiatric care was the most obvious, ANCOVA's were used to correct 6-month outcomes for baseline differences. A Mann-Whitney test was used for ordinal social network data. If significant between-group differences were found ( $p<.05$ ), an effect size was calculated according to the appropriate formulas (Field, 2005).

Since service use and therapeutic alliance were measured three times (at 0, 3 and 6 months), longitudinal analysis by means of Generalized Estimating Equations (GEE; Twisk, 2003) was used, in which we tested whether there was an effect of time and group between baseline, 3month, and 6-month follow-up. Again, corrections for baseline differences were made.

GEE-analyses were also used to assess the effect of the professional's ICPT-score (predictor) on both the patient's SRS-score and the professional's SRS-score (outcome) in the experimental group. Since GEE models are able to detect a predictor effect over time, while correcting for correlations between individual longitudinal measurements, GEE-analyses were used to assess whether differences in the use of ICPT-elements over time resulted in different session rating scores.

Interview data were descriptively analyzed per question, using both representative and deviating quotes to 
describe the range of replies. The scaling questions were analyzed as quantitative data, while explanations of scores were descriptively analyzed as above. Qualitative team supervision data was summarized into a list of issues discussed in supervision sessions, and analyzed to detect generic or recurring themes. Qualitative data were collected and assessed by a qualitative researcher who was informed of, but unrelated to the development and evaluation of ICPT. Summarized qualitative data from the team supervision meetings was member-checked with the team members and found valid.

\section{Results}

We recruited 36 patients, of whom 20 participated in the experimental ICPT program, and 16 received care as usual. All could be followed up at 3 and 6 months. Table 1 shows that participants have poor social functioning, have a high number of mental disorders on both DSM Axis I and Axis II, of which depressive, anxiety, and substance abuse disorders are the most frequent. Control group participants significantly more often have a job, have a higher income and have been in psychiatric care significantly shorter than participants in the experimental group (mean 4.3 versus 10.1 years).

\subsection{Outcome measures}

Overall, both groups improved in several areas over time (see Table 2) but a between-group difference was found in the extent of the social network. This increased significantly more in the experimental group then in the control group, showing a modest effect size of .34 .

\subsection{Process measures}

The quality of the therapeutic alliance, assessed at baseline, 3 months, and 6 months, was perceived as less positive by patients in both groups, while professionals were more positive in the experimental group. Treatment satisfaction of patients also decreased in both groups, but no between-group differences were found. Professionalperceived patient difficulty decreased in the experimental group but increased in the control group, resulting in a significant difference between groups (effect size .41). ICPT also resulted in a significantly lower use of outpatient services (corrected for other types of service use), showing a $30.1 \%$ decrease compared to a $7.7 \%$ increase in the control group. Another difference was found in the quality of the professional-rated therapeutic alliance, which significantly improved $(+5.7 \%)$ compared to care as usual $(-4.1 \%)$.

The ICPT scoring forms allowed measurement of the extent to which distinct ICPT-elements were used in the experimental group. ICPT-forms were filled out in 142 of 223 contacts $(63.7 \%)$ and showed a range of scores between 4 and 9.5 , with a mean of 7.6 (SD 1.3), indicating a relatively high use of ICPT-elements. The frequency of use of ICPT-elements varied widely, with assessing the treatment stage being the most (98.6\%) and negotiating goals the least (15.6\%) used.
The longitudinal relation between ICPT-fidelity and scores on the SRS was also studied, revealing conflicting results among patients and professionals. For patients, an increase of the ICPT-score did not result in a significant change of the SRS-score over time and participants. Professionals' higher ICPT-scores, however, resulted in higher SRS-scores: a significant $18.0 \%$ increase with 10 ICPT-points over a 6 -month period $(B=.719,95 \% \mathrm{CI}[.036-$ $1.402, p=.039$, Wald $=4.262, \mathrm{df}=1$ ). This means that the more ICPT-elements were used, the better the professional rated the session with the patient, while this had no effect on the session rating of the patient. Correction for the variable time did not change this association. The professional-perceived difficulty score, however, was a confounder, since the positive effect of a higher ICPT-score on professionals' SRS-scores was magnified by almost a factor three in more 'difficult' patients $(B=1.964,95 \% \mathrm{CI}$ [1.05-2.86], $p<.000$, Wald $=17.76, \mathrm{df}=1)$. This indicates that with more 'difficult' patients, a higher use of ICPTelements resulted in higher session ratings over time and between patients than in less 'difficult' patients.

\subsection{Semi-structured interviews (experimental group only)}

In patient interviews we asked to which extent participants noted changes in their treatment, and if specific well-recognizable ICPT-elements (e.g. agenda setting, goal setting, and SRS-administration) were carried out (see Table 3 ). Furthermore, we collected some ordinal data about their usefulness as perceived by patients. In general, out of the 35 judgements by 12 patients who reported changes, $60 \%(n=21)$ was positive, $11.4 \%(n=4)$ was negative, and $28.6 \%(n=10)$ was undecided (see outer right column of Table 3 for more details per ICPT-element). Professionals also rated the applicability and usefulness of ICPT through scale questions (1-10) about the training, the support, the program itself, and the supervision.

\subsubsection{Patients}

In the open-ended questions, the overarching themes were 'feeling heard' and 'session structure'. About a sixth of patients told they felt hardly listened to by their CPN, while another sixth part stated that they took the lead right from the start of the session. Almost three quarters of the participants appreciated the agenda setting as a useful tool to raise the chances of having their own subjects discussed in the session. They were able to make themselves better heard through its use. A quarter, however, found agenda-setting overly distant or had difficulties in coming up with subjects to talk about. Goal setting was more universally (four fifths of patients) perceived as helpful in focussing the sessions and the treatment in general. Some stated that even while goals were formulated, they were not worked on, nor evaluated. Another element, the filling out of the SRS at the session's conclusion, again had a more mixed reception. While most participants saw it as another way to increase the quality of the contact, a small minority was negative and felt that the SRS was overly formalistic, or was uncomfortable with judging their CPN in this way. 
Table 2

Outcome and process measures at baseline and 6-month follow-up.

\begin{tabular}{|c|c|c|c|c|c|c|}
\hline Type of measurement & Instrument & $\begin{array}{l}\text { Experimental } \\
\text { group }(n=20)\end{array}$ & Control group $(n=16)$ & $\begin{array}{l}p \text { (between } \\
\text { group) }\end{array}$ & $p$ (change) & $\begin{array}{l}\text { Overall } \\
\text { effect size }^{\mathrm{a}}\end{array}$ \\
\hline \multirow{8}{*}{$\begin{array}{l}\text { Psychiatric } \\
\text { symptoms }\end{array}$} & \multicolumn{6}{|l|}{ Patient-rated } \\
\hline & \multicolumn{6}{|l|}{ OQ-45 } \\
\hline & Baseline & $74.8(23.4)$ & $90.1(21.7)$ & .048 & \multirow[t]{3}{*}{.860} & \multirow[t]{3}{*}{-} \\
\hline & 6 months & $73.9(22.1)$ & $91.3(27.8)$ & .047 & & \\
\hline & \multirow{2}{*}{\multicolumn{6}{|c|}{$\begin{array}{l}\text { Professional-rated } \\
\text { HONOS }\end{array}$}} \\
\hline & & & & & & \\
\hline & Baseline & $12.4(5.2)$ & $15.1(4.2)$ & .100 & \multirow[t]{2}{*}{.640} & \multirow[t]{2}{*}{-} \\
\hline & 6 months & $11.1(6.2)$ & $13.7(6.3)$ & .243 & & \\
\hline \multirow{17}{*}{$\begin{array}{l}\text { Psychosocial } \\
\text { functioning }\end{array}$} & \multicolumn{6}{|l|}{ Patient-rated } \\
\hline & \multicolumn{6}{|c|}{ CANSAS met needs } \\
\hline & Baseline & $4.7(2.5)$ & $4.6(3.0)$ & .486 & \multirow[t]{2}{*}{.499} & \multirow[t]{2}{*}{-} \\
\hline & 6 months & $4.7(2.2)$ & $5.4(2.7)$ & .290 & & \\
\hline & \multicolumn{6}{|c|}{ CANSAS unmet needs } \\
\hline & Baseline & $5.1(3.3)$ & $5.0(4.7)$ & .420 & \multirow[t]{4}{*}{.206} & \multirow[t]{4}{*}{-} \\
\hline & 6 months & $1.7(2.3$ & $2.9(2.6)$ & .478 & & \\
\hline & \multirow{2}{*}{\multicolumn{4}{|c|}{$\begin{array}{l}\text { Professional-rated } \\
\text { CANSAS met needs }\end{array}$}} & & \\
\hline & & & & & & \\
\hline & Baseline & $4.2(2.0)$ & $3.8(3.5)$ & .632 & \multirow[t]{2}{*}{.320} & \multirow[t]{2}{*}{-} \\
\hline & 6 months & $6.5(3.1)$ & $5.3(2.2)$ & .229 & & \\
\hline & \multicolumn{6}{|c|}{ CANSAS unmet needs } \\
\hline & Baseline & $5.3(3.2)$ & $7.6(3.6)$ & .055 & .491 & - \\
\hline & 6 months & $4.2(3.7)$ & $6.2(3.8)$ & .114 & & \\
\hline & Professional-1 & & & & & \\
\hline & GAF & $46.2(7.7)$ & $47.4(6.0)$ & .621 & & \\
\hline & & $50.1(5.9)$ & $49.8(6.8)$ & .891 & .795 & - \\
\hline Activities and & Patient-rated & & & & & \\
\hline & Social netwo & & & & & \\
\hline & Baseline & 17.9 & 19.3 & .625 & .043 & .34 \\
\hline & 6 months & 20.0 & 15.3 & .153 & & \\
\hline & MANSA & & & & & \\
\hline & Baseline & $3.6(.8)$ & $3.5(1.0)$ & .749 & .159 & - \\
\hline & 6 months & $4.2(.9)$ & $3.6(1.0)$ & .116 & & \\
\hline Process & $\begin{array}{l}\text { Patient-rated } \\
\text { CSQ-8 }\end{array}$ & & & & & \\
\hline & Baseline & $23.6(5.9)$ & $20.5(4.5)$ & .088 & .683 & - \\
\hline & 6 months & 20.7 (6.9) & $20.4(3.9)$ & .856 & & \\
\hline & Professional- & & & & & \\
\hline & Difficulty scc & & & & & \\
\hline & Baseline & $4.0(1.4)$ & $4.4(.7)$ & .342 & .019 & .41 \\
\hline & 6 months & $3.6(1.3)$ & $4.5(.5)$ & .012 & & \\
\hline & STAR $^{\mathrm{C}}$ & & & & & \\
\hline & Baseline & $34.7(7.8)$ & $33.8(4.4)$ & .689 & .081 & - \\
\hline & 3 months & $35.4(9.2)$ & $32.8(6.3)$ & .362 & & \\
\hline & 6 months & $29.3(10.6)$ & $32.9(3.8)$ & .178 & & \\
\hline & $\begin{array}{l}\text { Professional- } \\
\text { STARC }^{-1}\end{array}$ & & & & & \\
\hline & Baseline & $35.3(4.7)$ & $31.9(3.1)$ & .020 & $<.001$ & - \\
\hline & 3 months & $38.1(4.2)$ & $31.4(3.9)$ & .000 & & \\
\hline & 6 months & $37.3(4.2)$ & $30.6(3.6)$ & .000 & & \\
\hline & Outpatient s & $\mathrm{use}^{\mathrm{c}, \mathrm{d}}$ & & & & \\
\hline & Baseline & $7.3(7.8)$ & $2.6(2.6)$ & .019 & .013 & - \\
\hline & 3 months & $5.4(4.5)$ & $3.9(3.6)$ & .281 & & \\
\hline & 6 months & $5.1(6.3)$ & $2.8(2.1)$ & .146 & & \\
\hline
\end{tabular}

\footnotetext{
${ }^{a}$ Effect sizes only given when significant at $p<.05$, not given for generalized estimating equations.

b Mann-Whitney test, due to ordinal data.

c Generalized estimated equations, each observation corrected for the previous observation (autoregression model).
}

d Poisson-distribution, due to skewed count data. 
Table 3

ICPT-elements: content, frequency of use, and perceived usefulness.

\begin{tabular}{|c|c|c|c|c|c|c|c|}
\hline & ICPT element & Goal & Score $^{\mathrm{a}}$ & $\begin{array}{l}\text { Frequency } \\
\text { (CPNs) }\end{array}$ & $\begin{array}{l}\text { Usefulness } \\
\text { (CPNs) }\end{array}$ & $\begin{array}{l}\text { Frequency } \\
\text { (patients) }^{\mathrm{b}}\end{array}$ & $\begin{array}{l}\text { Usefulness } \\
\text { (patients) }\end{array}$ \\
\hline 1 & Identifying treatment phase & Identification of stage 1 (alliance), 2 (goal setting), 3 (working) & 2 & $98.6 \%(140)$ & $6.7(1.4)$ & - & - \\
\hline 2 & Setting agenda & Joint agenda setting for the session & 1 & $63.1 \%(89)$ & $7.8(1.0)$ & $55 \%(11)$ & $\begin{array}{l}+: 55 \%(6) \\
-: 27 \%(3) \\
\pm: 18 \%(2)\end{array}$ \\
\hline 3 & Looking back & Looking back at the previous session to maintain a course & $1-1.5^{\mathrm{c}}$ & $80.9 \%(114)$ & $7.5(1.0)$ & - & - \\
\hline 4 & Clarifying expectations & Matching mutual expectations of the session & $2^{\mathrm{d}}$ & $36.9 \%(52)$ & $6.3(1.6)$ & - & - \\
\hline 5 & Inventarizing problems and needs & Inventory of needs according to structured instrument (CANSAS) & $2-2.5^{c}$ & $68.1 \%(96)$ & $6.7(2.9)$ & - & - \\
\hline 6 & Setting goals & Goal setting based upon needs & 2 & $25.5 \%(36)$ & $7.0(1.1)$ & $60 \%(12)$ & $\begin{array}{l}+: 75 \%(8) \\
-: 0 \%(0) \\
\pm: 25 \%(4)\end{array}$ \\
\hline 7 & Negotiating goals & Negotiating suitability and ranking order of goals & 2 & $15.6 \%(22)$ & $7.0(.6)$ & - & - \\
\hline 8 & Working towards goals & Active working on goals, using structured methods & 2 & $51.2 \%(73)$ & $7.3(.6)$ & - & - \\
\hline \multirow[t]{2}{*}{9} & Using SRS-forms & Collection of structured session feedback & 1.5 (patient) & $62.5 \%(85)$ & $7.0(1.2)$ & $60 \%(12)$ & $\begin{array}{l}+: 59 \%(7) \\
-: 8 \%(1) \\
\pm: 33 \%(2)\end{array}$ \\
\hline & & & 1 (clinician) & $97.2 \%(138)$ & $5.8(1.5)$ & - & - \\
\hline 10 & Using stage-specific methods & Using methods that fit the treatment phase & .5 & $72.5(100)$ & $-{ }^{d}$ & - & - \\
\hline
\end{tabular}

b No data collected on all items since some were hard to observe when unaware of.

c Exact score depends on the extent to which specific elements are used.

d Only one of the score from rows 4 to 8 may be obtained. 


\subsubsection{Professionals}

All participating CPNs and psychiatrists could be interviewed at 6-month follow up. In general, CPNs found the program sufficiently applicable (mean 7.3, SD 1.3). The usefulness of the program was given a mean score of 7.2 (SD 1.0). The offered support was hardly used, except in the biweekly team meetings, but the 3 CPNs that did use it felt well supported (mean 8.5, SD 1.0). The training was well evaluated in general (mean 7.8, SD .3) but lower on feeling prepared for practicing ICPT (mean 6.7, SD .5). More instruction was felt needed in some areas (e.g. goal setting, filling out of forms). More specific ratings were also given for each ICPT-element, as shown in Table 3 ( 7 th column).

Five overarching themes occurred in the data about the program itself: 'treatment structure', 'specific techniques', 'personal discipline', 'responsibility', and 'team support'. All CPNs acknowledged the positive effect of ICPT on structuring sessions, and treatment in general. Of the specific techniques, agenda setting (mean 7.8, SD 1.0), looking back at the previous session (mean 7.5, SD 1.0), and working towards goals (mean 7.3, SD .6) were considered highly useful. Although time-intensive, CPNs thought that these elements of ICPT enhanced the patient-professional cooperation. An often recurring theme concerned 'personal discipline' to maintain the structure as suggested in ICPT. During the research period in general, and shortly after the training in particular, CPNs reported higher fidelity to ICPT than later in the research period.

The content of supervision sessions, with few exceptions, concerned issues of responsibility. CPNs wondered to what extent they should interfere with patients' lives and decisions, and how they could entice patients to accept more personal responsibility in general. Despite the fact that supervision did not intent to, nor provided clear-cut answers to concrete questions, all CPNs highlighted the support they experienced from both the team and the supervisor, resulting in a score of 8.1 (SD .4) for its usefulness. This resulted in a better practice of what had been learned during the training, and a closer look into CPNs' personal functioning. CPNs' valued the focus on the treatment phase the patient they discussed was in. At the same time, they warned against the easy transition of supervision sessions into discussions about patients' treatment since the latter discussions minimized the proper analysis of contact and care patterns, and CPNs' personal involvement.

\section{Discussion}

In this controlled pilot study we found that Interpersonal Community Psychiatric Treatment (ICPT), is feasible for both patients and professionals. In qualitative interviews we found that patients rated ICPT largely positive, although the structure and focus on patientprofessional contact did not fit everyone. Professionals also generally rated ICPT positively in terms of feasibility and usefulness. ICPT, designed for patients with long-term non-psychotic disorders and their treating CPNs, did better than care as usual in one outcome measure (patient's social network size) and three process measures (patient's service use, professional-perceived difficulty and therapeutic alliance). In the longitudinal relation between ICPT-usage and session rating, a positive effect was found in professionals' ratings, especially in contact with more 'difficult' patients.

\subsection{Outcomes in relation to the goals and rationale of ICPT}

Looking at the broadly stated goal of ICPT, increase of effective behaviours, we preliminarily conclude that this was reached. Patients used less services, and became more socially active. Professionals used a high number of ICPTelements professionals use, resulting in better ratings of sessions, especially with more 'difficult' patients. To our knowledge, this is one of the first studies that looks into psychiatric nursing care for patients with long-term nonpsychotic disorders. Also, it is one of the first studies, although non-randomized, that reports positive outcomes of community psychiatric nursing treatment with nonpsychotic patients (e.g. Kendrick et al., 2005; Gournay and Brooking, 1994). In spite of several initiatives in particularly the UK but also elsewhere towards a more professional patient-centred practice (Couldwell and Stickley, 2007), a recent study still (MacNeela et al., 2010) found psychiatric nurses to do little shared decision making with their patients. Additional to earlier findings, we were able to show that CPNs may be able to use more structured and goal-oriented strategies within an atmosphere of shareddecision making.

One aspect of the results raises further questions: why patients became less content with the treatment process in both groups, but particularly (though not statistically significant) in the experimental group? Based on the qualitative interviews and the existing literature we are inclined to think that patients preferred the unstructured and non-demanding nature of care as usual, described elsewhere as 'pampering and dithering' (Koekkoek et al., 2009). The stronger emphasis on agenda and goal setting in ICPT may not have appealed to all of the patients. On the other hand, patients in the qualitative interviews praised the shared decision making elements of ICPT. They may be ambivalent about ICPT's intention to make them more active and responsible, since this requires more personal investment but also offers more personal power. The lower emphasis on the professional as an active expert may be explanatory for the lower ratings of these patients that have been in psychiatric care for a mean number of over ten years. In earlier work we found that patients may collude with professionals in order to prevent actual change (Koekkoek et al., 2008).

It is also noteworthy that professionals have seemed to benefit more from the intervention than patients did, illustrated by - for instance - their increased rating of the therapeutic relationship. This supports our previous findings in other studies, i.e. that 'difficult' patients are co-created by patients and professionals, and that the better professionals are equipped to work with complex treatment situations, the lower they score the 'difficulty' of their patients. It may also be that ICPT invited patients and professionals alike to behave more effectively, resulting in better outcomes - for patients especially outside treatment and for professionals especially within treatment. 


\subsection{Strengths}

The major strength of this study is its focus on a neglected group of psychiatric patients, its attempt to structure psychiatric nursing care, its introduction of shared decision making with these patients, and its rigorous support and scientific follow-up of both professionals and patients. All participants could be followed up at 3 and 6 months, probably due to a focused and personal approach using letters, phone calls, and - in some cases home visits.

Another strength of this study is its broad assessment of both process and outcome measures across several dimensions. The treatment itself, ICPT, is outlined and reported on in detail, enabling clinicians and researchers to weigh the potential benefits of the total program and the elements it consists of. The use of relatively modern statistical techniques, currently still little used in nursing and mental health care research, allows analysis of the treatment process over time. Another strength is the consistent focus on patient-rated and professional-rated measures. This facilitates a comparison between these two viewpoints but also shows that effective patient-professional cooperation is possible and may be supported by dually applied measures such as the CANSAS and the SRS.

\subsection{Limitations}

This study suffers from some limitations. The small sample size, although a pilot, and some differences between the experimental and control group warrant careful interpretation of the results. Given the relative unsuccessfulness of other, short-term treatments by CPNs (Kendrick et al., 2005) and the novelty of some elements of ICPT to CPNs (see also Koekkoek et al., 2010c), the intervention however first required a small, non-randomized study. Nevertheless, we have incorporated several strategies to counter the drawbacks of this approach, among which longitudinal data collection and nonparametrical data analysis to handle non-normally distributed samples. Analysis of the longitudinal relation between treatment dose (reflected by the ICPT-score) and experienced effect (reflected by patients' and professionals' SRS-score) reinforced the positive between-group effects. We do have to take into account, though, that social desirability may have induced CPNs to score their use of ICPT-elements higher than justified. Finally, qualitative data collection and analysis was primarily descriptive to facilitate better understanding of some outcomes.

\section{Conclusion}

ICPT appears to be a program that can successfully be carried out by CPNs, that is generally experienced as acceptable and useful by patients and professionals alike, and that results in positive results on both process and outcome, some superior to care as usual. Although this study has its limitations, the positive outcomes for both patients and professionals in a challenging care situation justify the execution of a full randomized study. With regard to the pilot status of this study, we note that both the treatment itself was well received, and the research evolved quite well. However, in the new instruction manual and training, more attention will be paid to the specifics of goals setting and the practice of motivational interviewing. In the main research study we may use a different diagnostic interview than the SCID, since it took quite long to administer - which may be problematic in the main study in which more patients will participate. This main study will include measurement of more characteristics of - preferably a larger number of CPNs to account for variation between professionals. Also, in order to reduce the chances of socially desirable answering by CPNs, the treatment integrity will be checked more intensively, for instance through audio-taping sessions, than we did in this pilot study.

\section{Acknowledgements}

We thank the patients and CPNs who participated in this research. Also we thank Natasja de Vries for data management, Wim de Vries for conducting interviews and Jos Twisk and Maarten Koeter for statistical advice.

\section{Conflicts of interest}

None declared.

\section{Funding}

This study was funded by ZonMW (The Netherlands Organisation for Health Care Research and Development) 'Geestkracht'-program (Grant 100-002-031), Health Care Insurers Innovation Fund (Grant 1728), Altrecht Mental Health Care and ProPersona Mental Health Care. None of these bodies had any role in the study design; the collection, analysis, and interpretation of data; the writing of the paper; or the decision to submit this paper for publication.

\section{Ethical approval}

The study was approved by the local research ethics committee at Altrecht Mental Health Care, the institution the 1 st author was affiliated with at the time of this study. Informed consent was obtained from all participants. Participants were provided with written and verbal information about the study.

\section{References}

Attkisson, C.C., Zwick, R., 1982. The client satisfaction questionnaire. Psychometric properties and correlations with service utilization and psychotherapy outcome. Evaluation and Program Planning 5 , 233-237.

Barr, W., 2000. Characteristics of severely mentally ill patients in and out of contact with community mental health services. Journal of Advanced Nursing 31, 1189-1198.

Bartholomew, L.K., Parcel, G.S., Kok, G., 1998. Intervention mapping: a process for developing theory- and evidence-based health education programs. Health Education \& Behavior 25, 545-563.

Bebbington, P., Brugha, T., Hill, T., Marsden, L., Window, S., 1999. Validation of the health of the nation outcome scales. British Journal of Psychiatry 174, 389-394.

Bowers, L., 1997. Community psychiatric nurse caseloads and the 'worried well': misspent time vital work? Journal of Advanced Nursing 26 930-936.

Breeze, J.A., Repper, J., 1998. Struggling for control: the care experiences of 'difficult' patients in mental health services. Journal of Advanced Nursing 28, 1301-1311. 
Burke, B.L., Arkowitz, H., Menchola, M., 2003. The efficacy of motivational interviewing: a meta-analysis of controlled clinical trials. Journal of Consulting and Clinical Psychology 71, 843-861.

Chisholm, D., Knapp, M.R., Knudsen, H.C., Amaddeo, F., Gaite, L., van Wijngaarden, B., 2000. Client socio-demographic and service receipt inventory-European version: development of an instrument for international research. EPSILON study 5. European psychiatric services: inputs linked to outcome domains and needs. British Journal of Psychiatry Supplement 39, s28-s33.

Couldwell, A., Stickley, T., 2007. The Thorn course: rhetoric and reality. Journal of Psychiatric and Mental Health Nursing 14, 625-634.

Curran, J., Brooker, C., 2007. Systematic review of interventions delivered by UK mental health nurses. International Journal of Nursing Studies 44, 479-509.

Dawson, D., MacMillan, H.L., 1993. Relationship Management of the Borderline Patient: From Understanding to Treatment. Brunner/ Mazel, New York.

de Jonge, J., 1995. Job Autonomy, Well-being, and Health: A Study Among Dutch Health Care Workers. Universitaire Pers Maastricht, Maastricht.

Duncan, B.L., Miller, S.D., Sparks, J.A., Claud, D.A., Reynolds, L.R., Brown, J., Johnson, L.D., 2003. The session rating scale: preliminary psychometric properties of a "working" alliance measure. Journal of Brief Therapy 3, 3-12.

Field, A., 2005. Discovering Statistics using SPSS. SAGE, London.

First, M.B., Spitzer, R.L., Gibbon, M., Williams, J.B.W., Davies, M., Borus, J., Howes, M.J., Kane, J., Pope, H.G., Rounsaville, B., 1995. The structured clinical interview for DSM-III-R personality disorders (SCID-II). Part II Multi-site test-retest reliability study. Journal of Personality Disorders 9, 92-104.

Goldman, H.H., Skodol, A.E., Lave, T.R., 1992. Revising axis V for DSM-IV: a review of measures of social functioning. American Journal of Psychiatry $149,1148-1156$.

Goossens, P.J., Beentjes, T.A., Leeuw, de J.A., Knoppert-van der Klein, E.A., Achterberg, van, T.A., 2008. The nursing of outpatients with a bipolar disorder: what nurses actually do. Archives of Psychiatric Nursing 22, $3-11$.

Gournay, K., Brooking, J., 1994. Community psychiatric nurses in primary health care. British Journal of Psychiatry 165, 231-238.

Gournay, K., 1995. Mental health nurses working purposefully with people with serious and enduring mental illness-an international perspective. International Journal of Nursing Studies 32, 341-352.

Hayward, M., Slade, M., Moran, P.A., 2006. Personality disorders and unmet needs among psychiatric inpatients. Psychiatric Services 57, 538-543.

Hinshelwood, R.D., 1999. The difficult patient. The role of 'scientific psychiatry' in understanding patients with chronic schizophrenia or severe personality disorder. British Journal of Psychiatry 174, 187-190.

Hoch, J.S., O'Reilly, R.L., Carscadden, J., 2006. Relationship management therapy for patients with borderline personality disorder. Psychiatric Services 57, 179-181.

Keller, M.B., McCullough, J.P., Klein, D.N., Arnow, B., Dunner, D.L., Gelenberg, A.J., Markowitz, J.C., Nemeroff, C.B., Russell, J.M., Thase, M.E., et al., 2000. A comparison of nefazodone, the cognitive behavioralanalysis system of psychotherapy, and their combination for the treatment of chronic depression. New England Journal of Medicine 342, 1462-1470.

Kendrick, T., Simons, L., Mynors-Wallis, L., Gray, A., Lathlean, J., Pickering, R., Harris, S., Rivero-Arias, O., Gerard, K., Thompson, C., 2005. A trial of problem-solving by community mental health nurses for anxiety, depression and life difficulties among general practice patients. The CPN-GP study. Health Technology Assessment 9, 1-104 iii.

Koekkoek, B., van Meijel, B., Hutschemaekers, G., 2006. "Difficult patients" in mental health care: a review. Psychiatric Services 57, 795-802.

Koekkoek, B., van Meijel, B., Schene, A., Hutschemaekers, G., 2008. Clinical problems in the long-term care of patients with chronic depression. Journal of Advanced Nursing 62, 689-697.

Koekkoek, B., van Meijel, B., Schene, A., Hutschemaekers, G., 2009. Problems in psychiatric care of 'difficult patients': a Delphi-study. Epidemiologia e Psichiatria Sociale 18, 323-330.

Koekkoek, B., van Meijel, B., Tiemens, B., Schene, A., Hutschemaekers, G., 2010a. What makes community psychiatric nurses label non-psychotic chronic patients as 'difficult': patient, professional, treatment and social variables. Social Psychiatry and Psychiatric Epidemiology, doi:10.1007/ s00127-010-0264-5.

Koekkoek, B., van Meijel, B., Hutschemaekers, G., 2010b. Community mental healthcare for people with severe personality disorder: narrative review. The Psychiatrist 34, 24-30.

Koekkoek, B., van Meijel, B., Schene, A., Hutschemaekers, G., 2010c. Development of an intervention program to increase effective behaviours by patients and clinicians in psychiatric services: Intervention Mapping study. BMC Health Services Research 10, 293.

Koekkoek, B., Hutschemaekers, G., van Meijel, B., Schene, A., 2011. How do patients come to be seen as 'difficult'? A mixed-methods study in community mental health care. Social Science and Medicine 72, 504512.

Lambert, M.J., Burlingame, G.M., Umphress, V., Hansen, N.B., Vermeersch, D.A., Clouse, G.C., et al., 1996. The reliability and validity of the outcome questionnaire. Clinical Psychology and Psychotherapy 3, 249-258.

Landeweerd, J.A., Boumans, N.P.G., Nissen, J.M.J.F., 1996. Arbeidsvoldoening bij verplegenden en verzorgenden. De Maastrichtse arbeidssatisfactieschaal voor de gezondheidszorg.(Work satisfaction in nursing personnel. The Maastricht Work Satisfaction Scale for health care). In: van Beek, C.C., van Dorsten, T.C., Stam, G.J. (Eds.), Handboek Verpleegkundige Innovatie. Bohn Stafleu, Loghem, Houten, pp. D250-3D250-26.

Linehan, M.M., 1993. Cognitive-Behavioral Treatment of Borderline Personality Disorder. Guilford Press, New York

MacNeela, P., Clinton, G., Place, C., Scott, A., Treacy, P., Hyde, A., Dowd, H., 2010. Psychosocial care in mental health nursing: a think aloud study. Journal of Advanced Nursing 66, 1297-1307.

McCullough, J.P., 2000. Treatment for Chronic Depression. Cognitive Behavioural Analysis System of Psychotherapy. The Guilford Press, New York.

McGuire-Snieckus, R., McCabe, R., Catty, J., Hansson, L., Priebe, S., 2007. A new scale to assess the therapeutic relationship in community mental health care: STAR. Psychological Medicine 37, 85-95.

Miller, W.R., Rollnick, S., 2002. Motivational interviewing. In: Preparing People for Change, Guilford Press, New York.

Montgomery, P., Rose, D., Carter, L., 2009. Patient health outcomes in psychiatric mental health nursing. Journal of Psychiatric and Mental Health Nursing 16, 32-45.

Phelan, M., Slade, M., Thornicroft, G., Dunn, G., Holloway, F., Wykes, T., Strathdee, G., Loftus, L., McCrone, P., Hayward, P., 1995. The Camberwell assessment of need: the validity and reliability of an instrument to assess the needs of people with severe mental illness. British Journal of Psychiatry 167, 589-595.

Priebe, S., Huxley, P., Knight, S., Evans, S., 1999. Application and results of the Manchester short assessment of quality of life (MANSA). International Journal of Social Psychiatry 45, 7-12.

Ruggeri, M., Leese, M., Thornicroft, G., Bisoffi, G., Tansella, M., 2000. Definition and prevalence of severe and persistent mental illness. British Journal of Psychiatry 177, 149-155.

Suber, R., 1994. Clinical Case Management: A Guide to Comprehensive Treatment of Serious Mental Illness. SAGE, London.

Torrey, W.C., Drake, R.E., Dixon, L., Burns, B.J., Flynn, L., Rush, A.J., Clark, R.E., Klatzker, D., 2001. Implementing evidence-based practices for persons with severe mental illnesses. Psychiatric Services 52, 4550.

Twisk, J.W.R., 2003. Applied Longitudinal Data Analysis for Epidemiology-A Practical Guide. Cambridge University Press, Cambridge.

Ustun, T.B., Chatterji, S., Bickenbach, J., Kostanjsek, N., Schneider, M., 2003. The international classification of functioning, disability and health: a new tool for understanding disability and health. Disability and Rehabilitation 25, 565-571.

WHO [World Health Organization], 2007. Atlas: Nurses in Mental Health. WHO, Geneva.

Williams, J.B., Gibbon, M., First, M.B., Spitzer, R.L., Davies, M., Borus, J., Howes, M.J., Kane, J., Pope Jr., H.G., Rounsaville, B., et al., 1992. The structured clinical interview for DSM-III-R (SCID). II. Multisite testretest reliability. Archives of General Psychiatry 49, 630-636.

Ziguras, S.J., Stuart, G.W., 2000. A meta-analysis of the effectiveness of mental health case management over 20 years. Psychiatric Services $51,1410-1421$. 